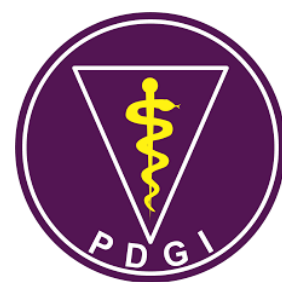

\title{
In vitro Antibiofilm Activity of Pomegranate (Punica granatum) Juice on Oral Pathogens
}

\author{
Jemima Pramadita ${ }^{1}$, Armelia Sari Widyarman ${ }^{2 \S}$ \\ ${ }^{1}$ Undergraduate student, Faculty of Dentistry, Trisakti University, Indonesia \\ ${ }^{2}$ Department of Microbiology, Faculty of Dentistry, Trisakti University, Indonesia
}

Received date: November 13, 2018. Accepted date: February 25, 2019. Published date: April 30, 2019.

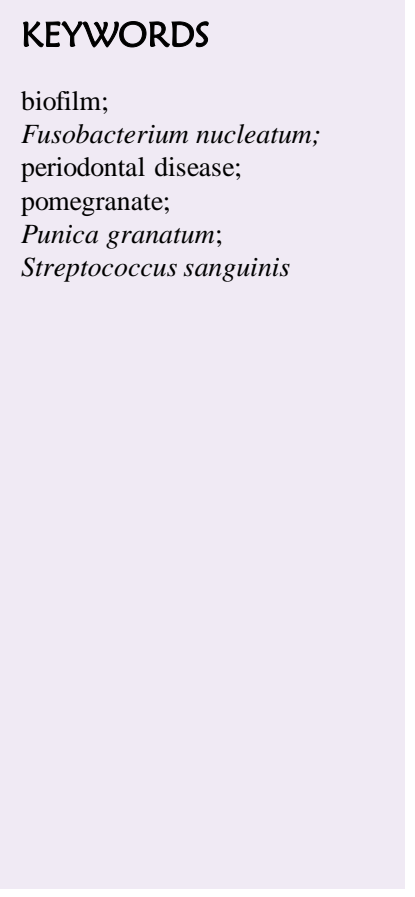

\begin{abstract}
Introduction: Pomegranate (Punica granatum) fruit contains valuable ingredients, such as ellagitannins and flavonoids, that have many potential effects, including antibacterial, antifungal, and anti-inflammatory functions. Objectives: The aim of this study was to investigate the effects of pomegranate fruit juice on $F$. nucleatum and $S$. sanguinis monospecies and multispecies biofilm formation in vitro. Methods: Pomegranate juice was obtained using a juicer and diluted using a brain heart infusion (BHI) broth into five different concentrations. The biofilm assay was performed as follows: F. nucleatum and S. sanguinis were cultured separately in the BHI broth for 48 hours at $37^{\circ} \mathrm{C}$ in an anaerobic atmosphere. A $200 \mu \mathrm{L}$ bacterial suspension $\left(10^{7} \mathrm{CFU} / \mathrm{mL}\right)$ was distributed into a 96 -well plate and incubated for 24 hours to form a biofilm. Subsequently, pomegranate juice was added to the biofilm well and observed after 1 hours, 3 hours, 6 hours, and 24 hours. The biofilm mass was measured using a microplate reader $(490 \mathrm{~nm})$ after crystal violet staining. Chlorhexidine $(0.2 \%)$ and the biofilms without treatment were used as the positive and negative controls, respectively. The data were statistically analyzed using one-way analysis of variance, with $p<0.05$ as the level of significance. Result: There was a significant biofilm reduction after treatment with pomegranate juice for all the concentrations and incubation times $(p<0.05)$. The effective concentrations to inhibit the biofilm monospecies $F$. nucleatum and $S$. sanguinis and the multispecies were $6.25 \%$ (OD $0.148 \pm 0.019$ ), $50 \%$ (OD $0.211 \pm 0.026$ ), and $6.25 \%$ (OD $0.024 \pm 0.209$ ), respectively. Conclusion: Pomegranate juice inhibits $F$. nucleatum and $S$. sanguinis biofilm formation as a monospecies and a multispecies. Future studies are needed to observe the mechanism of this active substance.
\end{abstract}

$\S$ Corresponding Author

E-mail address: armeliasari@trisakti.ac.id (Widyarman AS)

\section{DOI: https://doi.org/10.32793/jida.v2i1.353}

Copyright: (02019 Pramadita J, Widyarman AS. This is an open access article distributed under the terms of the Creative Commons Attribution License, which permits unrestricted use, distribution, and reproduction in any medium provided the original author and sources are credited. 


\section{INTRODUCTION}

Periodontal disease is recognized as a primary oral disease in several countries. ${ }^{1}$ According to the World Health Organization, it is present in 15\%-20\% of adults aged 35-45 years worldwide. ${ }^{2}$ The results of an Indonesian health survey (RISKESDAS, 2007) indicated that periodontal disease is the most prevalent of all oral conditions, at $96.58 \%$ across all age groups. ${ }^{3}$ A chronic inflammatory condition, periodontal disease affects periodontal tissue, gradually damaging the alveolar bone. ${ }^{4}$ The inflammation and destruction of periodontal tissue are mechanisms of the host response to a microbial biofilm that contains pathogenic Gram-negative bacteria. ${ }^{5}$ Periodontal disease is associated with several clinical symptoms. For example, gingivitis is an inflammatory condition caused by the accumulation of bacteria in the gingival margin. Periodontitis is an advanced inflammatory disease that frequently results in the destruction of the tooth's periodontal tissue. The clinical symptoms of periodontitis include deeper periodontal pockets and detachment, which eventually lead to tooth loss. ${ }^{1}$

One of the Gram-negative bacteria associated with periodontal disease is Fusobacterium nucleatum. ${ }^{5} \mathrm{~F}$. nucleatum is frequently present in subgingival plaque and the periodontal pockets. ${ }^{6}$ This bacterium plays an important role in adhesion reaction and coaggregation with other pathogenic microbes such as Porphyromonas gingivalis. ${ }^{6}$ Streptococcus sanguinis, another dominant Gram-positive bacterium in the oral cavity, is also a key contributor to the process of bacterial colonization. In contrast to $F$. nucleatum, however, $S$. sanguinis has antibacterial properties that assist in inhibiting the propagation of pathogenic periodontal bacteria. ${ }^{7}$ An earlier study indicated a possible connection between aggressive periodontitis and diminished $S$. sanguinis loads. ${ }^{8}$

Several treatments and medications aimed at targeting periodontal disease are available, including scaling, antibiotics, mouth rinses, and even preventive treatments. Nonetheless, the prevalence of periodontal disease remains high. Herbal substances offer natural alternatives for the treatment of periodontal disease, with several plant extracts containing bioactive compounds that have been proven to reduce pathogen invasion in the oral cavity. ${ }^{9}$ Recent studies have shown that strawberry extract can reduce the biofilm formation of Enterococcus faecalis and Porphyromonas gingivalis in vitro, ${ }^{10}$ mangosteen pericarp extracts are able to combat the cariogenic bacteria Streptococcus mutans, ${ }^{11}$ and bromelain enzymes obtained from pineapple stems possess effective antibacterial properties against $E$. faecalis. ${ }^{12}$
Pomegranate fruit (Punica granatum) has been shown to have significant potency as a bactericidal, antifungal, and antiviral agent. ${ }^{7}$ It is also known to modulate the immune system and is beneficial to the digestive system as a vermifuge (anthelmintic agent), an appetite stimulant, and a laxative agent. $P$. granatum has been used to treat cardiovascular disease, diabetes, diarrhea, asthma, bronchitis, cough, bleeding disorders, fever, swelling, acquired immunodeficiency syndrome (AIDS), dyspepsia, ulcers, bruising, open wounds, oral lesions, skin lesions, malaria, prostate cancer, hypertension, denture stomatitis, male infertility, vaginitis, Alzheimer's disease, and obesity. ${ }^{13,14}$ In this study, the effects of pomegranate juice on $F$. nucleatum and $S$. sanguinis monospecies and multispecies biofilm formation were observed in vitro.

\section{MATERIAL AND METHODS}

This study is an in vitro experimental laboratory design that was conducted at the Microbiology Centre of Research and Education (MiCORE) Laboratory, Faculty of Dentistry, Trisakti University, Jakarta, Indonesia. Fresh pomegranate fruits were collected from Tangerang, Java Island, Indonesia, and a phytochemical assay analysis was performed at the Indonesian Medicinal and Aromatic Crops Research Institute (BALITTRO) in Bogor, Indonesia.

\section{Pomegranate Juice Extract}

The fresh pomegranate fruits were washed and peeled and the seeds removed. The juice was then extracted in a juicer, centrifuged at $1500 \mathrm{rpm}$, and filtered using Whatman No. 1 filter paper. The juice extract was diluted with a brain heart infusion (BHI) broth in five different concentrations of $100 \%, 50 \%, 25 \%, 12.5 \%$, and $6.25 \%(\mathrm{v} / \mathrm{v})$.

\section{Biofilm Assay}

Fusobacterium nucleatum ATCC 25586 and S. sanguinis ATCC 10556 were individually inoculated into the BHI broth and incubated for 48 hours at $37^{\circ} \mathrm{C}$ in an anaerobic atmosphere $\left(\mathrm{CO}_{2}, \mathrm{H}, \mathrm{N}\right)$. The bacterial suspension from the incubation was measured at $600 \mathrm{~nm}$, diluted until $1.5 \times 10^{8} \mathrm{CFU} / \mathrm{mL}$, then homogenized using a vortexer. It was subsequently distributed into a 96-well plate and incubated at $37^{\circ} \mathrm{C}$ for 48 hours. Following the removal of planktonic bacteria, the pomegranate juice extract was added in various concentrations into the biofilm wells, and the inhibitory effect was observed after 1 hours, 3 hours, 6 hours, and 24 hours. The supernatant was removed, and the biofilm well plate was rinsed with a phosphate buffer saline. Crystal violet dye $(0.5 \% \mathrm{w} / \mathrm{v})$ was used to measure the $F$. nucleatum and $S$. 
sanguinis biofilm loads in the microplate wells. Up to $200 \mu \mathrm{L}$ of $90 \%$ ethanol was added, and the remaining crystal violet dye was measured using a microplate reader at $600 \mathrm{~nm}$. The BHI broth served as the negative control sample, while $0.2 \%$ chlorhexidine was used as the positive control.

\section{Statistical Analysis}

The data in this study were observed using three analytical methods: the Kolmogorov-Smirnov test, a oneway analysis of variance test, and a post hoc test. Statistical significance was set at $\mathrm{p}<0.05$.

\section{RESULT}

The results of the $P$. granatum phytochemical test revealed that the active substances present in the extract were saponin, tannin, flavonoids, and glycoside. The results of the phytochemical test are presented in Table 1. These results indicated that $P$. granatum juice extract significantly inhibits biofilm growth. The graph illustrates that the most effective inhibitory effect on $F$. nucleatum was achieved with a $6.25 \%$ (v/v) concentration following a 24 hours incubation period (Fig. 1). Meanwhile, a $100 \%$ (v/v) concentration incubated for $6 \mathrm{~h}$ exhibited the optimal inhibitory effect on S. sanguinis bacteria (Fig. 2). The most effective concentration for inhibiting the multispecies biofilm was $6.25 \%(\mathrm{v} / \mathrm{v})$ incubated for 24 hours (Fig. 3). The statistical results showed that there was a significant reduction in biofilm mass after treatment with the $P$. granatum fruit extract of each concentration and incubation period compared to the negative control $(\mathrm{p}<0.05)$.

\section{F. nucleatum Biofilms}

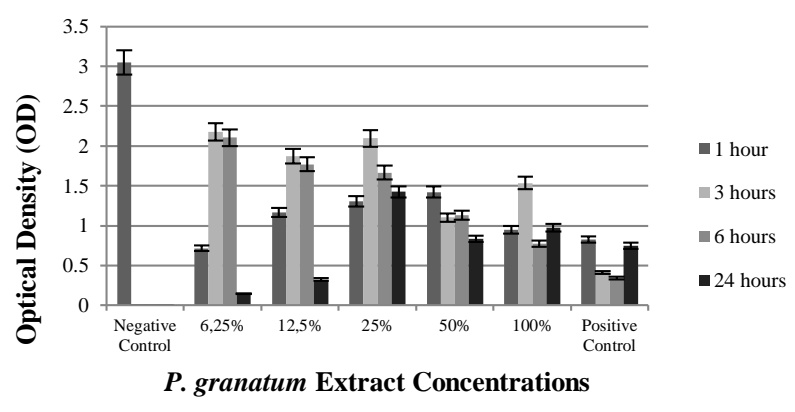

Figure 1. A graph showing $P$. granatum's inhibitory effect on $F$. nucleatum biofilm formation. The vertical axis indicates the $F$. nucleatum biofilm mass in terms of optical density (OD). The horizontal axis indicates the concentration of $P$. granatum fruit extract $(6.25 \%$, $12.5 \%, 25 \%, 50 \%, 100 \%$ ) after incubation for $1 \mathrm{~h}, 3 \mathrm{~h}, 6$ $\mathrm{h}$, and $24 \mathrm{~h}$. Chlorhexidine (CHX) $0.2 \%$ was used as the positive control, and biofilm without treatment was used as the negative control.

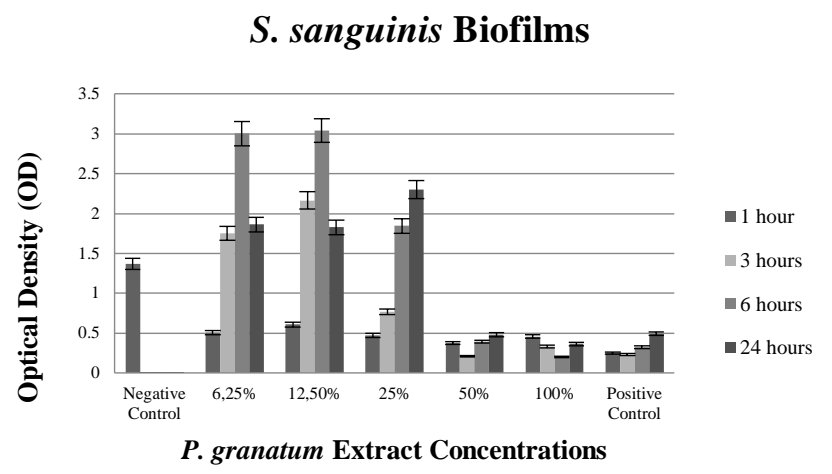

Figure 2. A graph showing $P$. granatum's inhibitory effect on a $S$. sanguinis biofilm formation. The vertical axis indicates the $S$. sanguinis biofilm mass in terms of optical density (OD). The horizontal axis indicates the concentration of $P$. granatum fruit extract $(6.25 \%$, $12.5 \%, 25 \%, 50 \%, 100 \%$ ) after incubation for $1 \mathrm{~h}, 3 \mathrm{~h}, 6$ $\mathrm{h}$, and $24 \mathrm{~h}$. Chlorhexidine (CHX) $0.2 \%$ was used as the positive control, and biofilm without treatment was used as the negative control.

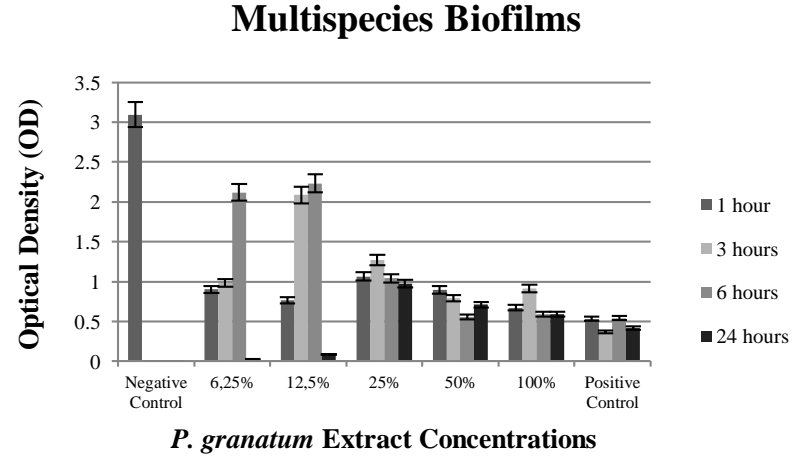

Figure 3. A graph showing $P$. granatum's inhibitory effect on a multispecies biofilm formation. The vertical axis indicates the multispecies biofilm mass in terms of optical density (OD). The horizontal axis indicates the concentration of $P$. granatum fruit extract $(6.25 \%$, $12.5 \%, 25 \%, 50 \%, 100 \%$ ) after incubation for $1 \mathrm{~h}, 3 \mathrm{~h}, 6$ $\mathrm{h}$, and $24 \mathrm{~h}$. Chlorhexidine (CHX) $0.2 \%$ was used as the positive control, and biofilm without treatment was used as the negative control.

Table 1. The results of the phytochemical assay analysis

\begin{tabular}{llcc}
\hline Samples & \multicolumn{1}{c}{ Materials } & Result & $\begin{array}{c}\text { Test } \\
\text { Method }\end{array}$ \\
\hline $\begin{array}{l}\text { Pranatum } \\
\text { extract }\end{array}$ & $\begin{array}{l}\text { Phytochemical } \\
\text { test }\end{array}$ & & Qualitative \\
& - Alkaloid & - & \\
& - Saponin & + & \\
& - Tannin & + & \\
& - Phenolic & - & \\
& - Flavonoid & + & \\
& - Triterpenoid & - & \\
& - Steroid & - & \\
& - Glycoside & + & \\
\hline
\end{tabular}




\section{DISCUSSION}

The test results indicated that the optimal inhibitory effect on $F$. nucleatum was achieved using a $6.25 \%(\mathrm{v} / \mathrm{v})$ concentration of $P$. granatum extract for an incubation period of 24 hours. The same test applied to S. sanguinis bacteria indicated an optimal inhibitory effect using a $100 \%(\mathrm{v} / \mathrm{v})$ concentration over a $6 \mathrm{~h}$ incubation period. However, Fig. 2 reveals a higher optical density (OD) at the $6.25 \%$ and $12.5 \%$ concentrations in comparison to the negative control after incubation for $3 \mathrm{~h}, 6 \mathrm{~h}$, and $24 \mathrm{~h}$. Furthermore, the $25 \%$ concentration had a higher OD in comparison to the negative control after the $6 \mathrm{~h}$ and $24 \mathrm{~h}$ incubation periods. This suggests lower concentrations of $P$. granatum are less effective in inhibiting $S$. sanguinis biofilm formation after a $1 \mathrm{~h}$ incubation period.

Previous studies have indicated that $S$. sanguinis can utilize sources of carbohydrate to survive. More than 50 putative carbohydrate transporters have been identified, including phosphotransferase enzymes, which are specifically associated with the transportation of glucose, fructose, mannose, galactitol, and maltose. The bacteria therefore have access to a robust means of energy production from sugar fermentation, ${ }^{7}$ including glucose, which is the main sugar present in $P$. granatum extract. The antibacterial effects of the pure substances in $P$. granatum can generally be attributed to their phenolic structure. The causal mechanisms of phenolic toxicity against microorganisms, including enzyme inhibition by oxidized substances, are reactions with sulfhydryl groups or nonspecific interactions with proteins, which can cause inactivity and protein loss. ${ }^{15}$

Microbial cells' targets are adhesion to the surface of polypeptide cell walls and to enzymes on the membrane. Phenol can also render a substance inhospitable to microorganisms, ${ }^{15}$ and high-performance liquid chromatography analysis has revealed that the primary phenolic substances in pomegranate are gallic acid, ellagic acid, and punicalagin as the main ellagitannin. ${ }^{16}$ We may therefore speculate that these substances are responsible for antimicrobial activity although it is possible that another, unidentified substance also contributes to this action. ${ }^{16} \mathrm{~A}$ recent study showed that pomegranate juice effectively inhibits the biofilm formation of $P$. gingivalis, A. actinomycetemcomitans, and T. denticola in vitro. ${ }^{17}$

Tannins are among those substances that contribute to the antibacterial properties of $P$. granatum. This substance is toxic to microorganisms and may affect the movement of substances into a cell owing to hydrophilic tannins' interactions with the membrane's polar end, while hydrophobic tannins penetrate the bacterial membrane's non-polar region, resulting in membrane instability. ${ }^{16}$ Tannin contributes to biofuel formation by precipitating vital proteins and can alter surface loads, interfering with substratum cell interactions and biofilm formation. The tannin and ellagic acid found in pomegranate fruit can induce astringency, which is associated with biofilm disruption. Several studies have indicated that the anti-biofilm properties of tannins may be attributable to quorum sensing inhibition. ${ }^{18}$

Several phytochemical substances present in pomegranate juice extract have demonstrated antimicrobial activity, and the majority of related studies have found that greater proportions of ellagic acid and hydrolyzed tannins, such as punicalagin, are associated with higher levels of antimicrobial activity. ${ }^{19}$ Previous studies have observed a connection between the antimicrobial effects of tannins and their toxicity and molecular structures. Tannins can interfere with cell walls and penetrate cell membranes because they precipitate protein and suppress glycosyltransferase enzymes. A study demonstrated that gallic acid (tannic acid) exhibited the strongest antimicrobial effect on the tested sensitive strain, even at a low concentration. The antimicrobial properties of $P$. granatum may therefore be related to its polyphenolic structure, which causes it to interact with bacterial cell walls, inhibit enzymes as an oxidizing agent, interact with proteins, and disrupt microorganism aggregation. ${ }^{20}$

F. nucleatum facilitates bacterial aggregation, and $S$. sanguinis is typically the first bacterium to colonize on a tooth's surface..$^{21}$ The interruption of these bacterial growths can inhibit bacterial colonization in the oral cavity. Quorum sensing is a signal delivery mechanism between cells and is used by bacteria colonies to communicate and promote their survival in terms of, for example, nutrition sources, microorganism defenses, virulent activity, and biofilm formation. ${ }^{22}$ The disruption of this mechanism is a key strategy for managing disease. Pomegranate juice have been shown to inhibit the quorum sensing signals of two bacterial strains, disrupt violet pigment production, and affect the motility levels of Chromobacterium violaceum and Pseudomonas aeruginosa bacteria. ${ }^{23}$ The inhibition process is caused by the direct and indirect disruption of quorum sensing, which is in turn caused by the polyphenolic structure of the pomegranate fruit or the interactive effects of a different substance within the extract. ${ }^{19}$

Flavonoids, which are also found in $P$. granatum extract, work to form complex compounds against extracellular protein and to disrupt the integrity of bacterial membrane cells. The causal mechanism is the denaturizing of bacterial protein cells and the infliction of damage to the cell membranes to the point of irreparability. Flavonoids also have antiseptic properties, forming complex compounds with different cells in the bacterial cell wall or extracellular protein, which can 
disrupt bacterial growth. ${ }^{24}$ The antimicrobial effects of $P$. granatum on pathogenic bacteria render it an effective and natural alternative antibacterial treatment; however, further investigation incorporating several bacterial groups is required to ascertain the relationship between antimicrobial activity and polyphenolic substances. The identification of the antimicrobial agents in $P$. granatum extract has yielded valuable information. ${ }^{16}$ Several synthetic substances have exhibited promising antibiofilm properties, but medicines derived from natural substances are superior with regard to production costs and success rates. ${ }^{18}$ Pomegranate fruits are among the several natural fruits that promise many benefits, and this study has demonstrated the antibacterial effects of $P$. granatum extract on $F$. nucleatum and $S$. sanguinis biofilms.

\section{CONCLUSION}

Based on this study, it may be concluded that $P$. granatum extract has antimicrobial effects on $F$. nucleatum monospecies, S. sanguinis monospecies, and $F$. nucleatum and $S$. sanguinis multispecies. $P$. granatum can be considered for use as an alternative antibacterial agent to inhibit bacterial growth in the oral cavity. Further studies are necessary to observe the mechanisms of the active substances in $P$. granatum extract, the antibacterial effects on other bacterial groups in the oral cavity, and its benefits for dentistry.

\section{CONFLICT OF INTEREST}

The authors declare that they have no conflicts of interest.

\section{REFERENCES}

1. Petersen PE, Ogawa H. The global burden of periodontal disease: towards integration with chronic disease prevention and control. Periodontol 2000. 2012;60: 15-39.

2. Kim HY, Park JB. In vitro evaluation of anticaries effect of cinnamon extracts on oral pathogens. Biomed Res. 2017;28(6):2848-2853.

3. Wijaksana IKE. Infectobesity dan periodontitis: hubungan dua arah obesitas dan penyakit periodontal. Odonto Dent J. 2016;3(1):67-73.

4. Di Benedetto A, Gigante I, Colucci S, Grano M. Periodontal disease: linking the primary inflammation to bone loss. Clin Dev Immunol. 2013;503754:1-7.

5. Signat B, Roques C, Poulet P, Duffaut D. Fusobacterium nucleatum in periodontal health and disease. Curr Issues Mol Biol. 2011;13(2):25-36.

6. Polak D, Wilensky A, Shapira L, Halabi A, Goldstein K, Weiss El, et al. Mouse model of experimental periodontitis induced by
Porphyromonas gingivalis/Fusobacterium nucleatum infection: bone loss and host response. J Clin Periodontol. 2009;36(5):406-10.

7. Ma S, Li H, Yan C, Wang D, Li H, Xia X, et al. Antagonistic effect of protein extracts from Streptococcus sanguinis on pathogenic bacteria and fungi of the oral cavity. Exp Ther Med. 2014;7(6):1486-94.

8. Stingu CS, Eschrich K, Rodloff AC, Schaumann R, Jentsch H. Periodontitis is associated with a loss of colonization by Streptococcus sanguinis. J Med Microbiol. 2008;57:495-99.

9. Widyarman AS, Sumadi S, Agustin TP. Antibiofilm effect of Clitoria ternatea flower juice on Porphyromonas gingivalis in vitro. J Indones Dent Assoc. 2018; 1(1):7-12. doi:10.32793/jida.v1i1.288.

10. Widyarman AS, Widjaja SB, Idrus E. Strawberry extract's effects on Enterococcus faecalis and Porphyromonas gingivalis biofilms in vitro. Sci Dent J. 2017;1(1):1-5.

11. Janardhanan S, Mahendra J, Girija ASS, Mahendra L, Priyadharsini V. Antimicrobial effects of Garcinia mangostana on cariogenic microorganisms. J Clin Diagn Res. 2017; 11(1): ZC19-ZC22.

12. Liliany D, Widyarman AS, Erfan E, Sudiono J, Djamil MS. Enzymatic activity of bromelain isolated pineapple (Ananas comosus) hump and its antibacterial effect on Enterococcus faecalis. Sci Dent J. 2018;2(2):39-50.

13. Prasad D, Kunnaiah R. Punica granatum: A review on its potential role in treating periodontal disease. $\mathrm{J}$ Indian Soc Periodontol. 2014;18(4):428-32.

14. Miguel MG, Neves MA, Antunes MD. Pomegranate (Punica granatum L.): A medicinal plant with myriad biological properties - A short review. J Med Plants Res. 2010;4(25):2836-47.

15. Naz S, Siddiqi R, Ahmad S, Rasool SA, Sayeed SA. Antibacterial activity directed isolation of compounds from Punica granatum. J Food Sci. 2007;72(9):M341-5.

16. Betanzos-Cabrera G, Montes-Rubio PY, FabelaIllescas HE, Belefant-Miller H, Cancino-Diaz JC. Antibacterial activity of fresh pomegranate juice against clinical strains of Staphylococcus epidermidis. Food Nutr Res. 2015;59:27620.

17. Widyarman AS, Suhalim OP, Nandary D, Theodorea CF. Pomegranate juice inhibits periodontal pathogens biofilm in vitro. Sci Dent J. 2018;2(3):101-108.

18. Bakkiyaraj D, Nandhini JR, Malathy B, Pandian SK. The anti-biofilm potential of pomegranate (Punica granatum L.) extract against human bacterial and fungal pathogens. Biofouling. 2013;29(8):929-937.

19. Howell AB, D'Souza DH. The pomegranate: effects on bacteria and viruses that influence human health. Evid Based Complement Alternat Med. 2013;2013:606212. 
20. Abdollahzadeh S, Mashouf R, Mortazavi H, Moghaddam M, Roozbahani N, Vahedi M. Antibacterial and antifungal activities of Punica granatum peel extracts against oral pathogens. J Dent Tehran Iran. 2011;8(1):1-6.

21. Huang R, Li M, Gregory RL. Bacterial interactions in dental biofilm. Virulence. 2011;2(5):435-44.

22. Li Y-H, Tian X. Quorum sensing and bacterial social interactions in biofilms. Sensors (Basel). 2012;12(3):2519-38.
23. Vasavi HS, Arun AB, Rekha P-D. Anti-quorum sensing potential of Adenanthera pavonina. Pharmacognosy Res. 2015;7(1):105-9.

24. Mahboubi A, Asgarpanah J, Sadaghiyani PN, Faizi M. Total phenolic and flavonoid content and antibacterial activity of Punica granatum L. var. pleniflora flowers (Golnar) against bacterial strains causing foodborne diseases. BMC Complement Altern Med. 2015;15:366. 